NASA/TM-2004-213203

ARL-TR-3252
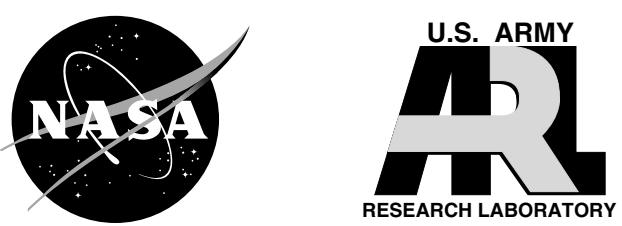

\title{
Evaluation of an Enhanced Bank of Kalman Filters for In-Flight Aircraft Engine Sensor Fault Diagnostics
}

Takahisa Kobayashi

QSS Group, Inc., Cleveland, Ohio

Donald L. Simon

U.S. Army Research Laboratory, Glenn Research Center, Cleveland, Ohio 
Since its founding, NASA has been dedicated to the advancement of aeronautics and space science. The NASA Scientific and Technical Information (STI) Program Office plays a key part in helping NASA maintain this important role.

The NASA STI Program Office is operated by Langley Research Center, the Lead Center for NASA's scientific and technical information. The NASA STI Program Office provides access to the NASA STI Database, the largest collection of aeronautical and space science STI in the world. The Program Office is also NASA's institutional mechanism for disseminating the results of its research and development activities. These results are published by NASA in the NASA STI Report Series, which includes the following report types:

- $\quad$ TECHNICAL PUBLICATION. Reports of completed research or a major significant phase of research that present the results of NASA programs and include extensive data or theoretical analysis. Includes compilations of significant scientific and technical data and information deemed to be of continuing reference value. NASA's counterpart of peerreviewed formal professional papers but has less stringent limitations on manuscript length and extent of graphic presentations.

- TECHNICAL MEMORANDUM. Scientific and technical findings that are preliminary or of specialized interest, e.g., quick release reports, working papers, and bibliographies that contain minimal annotation. Does not contain extensive analysis.

- CONTRACTOR REPORT. Scientific and technical findings by NASA-sponsored contractors and grantees.
- CONFERENCE PUBLICATION. Collected papers from scientific and technical conferences, symposia, seminars, or other meetings sponsored or cosponsored by NASA.

- SPECIAL PUBLICATION. Scientific, technical, or historical information from NASA programs, projects, and missions, often concerned with subjects having substantial public interest.

- TECHNICAL TRANSLATION. Englishlanguage translations of foreign scientific and technical material pertinent to NASA's mission.

Specialized services that complement the STI Program Office's diverse offerings include creating custom thesauri, building customized databases, organizing and publishing research results ... even providing videos.

For more information about the NASA STI Program Office, see the following:

- Access the NASA STI Program Home Page at http://www.sti.nasa.gov

- E-mail your question via the Internet to help@sti.nasa.gov

- Fax your question to the NASA Access Help Desk at 301-621-0134

- Telephone the NASA Access Help Desk at 301-621-0390

- Write to:

NASA Access Help Desk

NASA Center for AeroSpace Information 7121 Standard Drive

Hanover, MD 21076 
NASA/TM-2004-213203

ARL-TR-3252
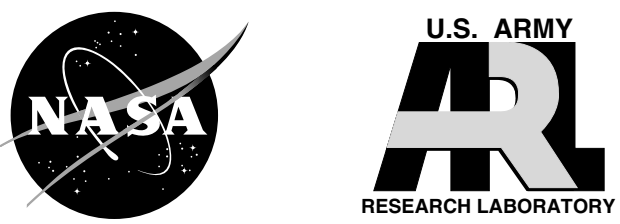

\section{Evaluation of an Enhanced Bank of Kalman Filters for In-Flight Aircraft Engine Sensor Fault Diagnostics}

Takahisa Kobayashi

QSS Group, Inc., Cleveland, Ohio

Donald L. Simon

U.S. Army Research Laboratory, Glenn Research Center, Cleveland, Ohio

Prepared for the

Turbo Expo 2004

sponsored by the American Society of Mechanical Engineers

Vienna, Austria, June 14-17, 2004

National Aeronautics and

Space Administration

Glenn Research Center 


\section{Acknowledgments}

This research was funded by the NASA Aviation Safety Program as a task under the Propulsion System Safety Technologies Element.

Available from

NASA Center for Aerospace Information 7121 Standard Drive

Hanover, MD 21076
National Technical Information Service 5285 Port Royal Road Springfield, VA 22100

Available electronically at http:/ /gltrs.grc.nasa.gov 


\section{EVALUATION OF AN ENHANCED BANK OF KALMAN FILTERS FOR IN-FLIGHT AIRCRAFT ENGINE SENSOR FAULT DIAGNOSTICS}

\author{
Takahisa Kobayashi \\ QSS Group, Inc. \\ Cleveland, Ohio 44135
}

\author{
Donald L. Simon \\ U.S. Army Research Laboratory \\ Glenn Research Center \\ Cleveland, Ohio 44135
}

\begin{abstract}
In this paper, an approach for in-flight fault detection and isolation (FDI) of aircraft engine sensors based on a bank of Kalman filters is developed. This approach utilizes multiple Kalman filters, each of which is designed based on a specific fault hypothesis. When the propulsion system experiences a fault, only one Kalman filter with the correct hypothesis is able to maintain the nominal estimation performance. Based on this knowledge, the isolation of faults is achieved. Since the propulsion system may experience component and actuator faults as well, a sensor FDI system must be robust in terms of avoiding misclassifications of any anomalies. The proposed approach utilizes a bank of $(m+1)$ Kalman filters where $m$ is the number of sensors being monitored. One Kalman filter is used for the detection of component and actuator faults while each of the other $m$ filters detects a fault in a specific sensor. With this setup, the overall robustness of the sensor FDI system to anomalies is enhanced. Moreover, numerous component fault events can be accounted for by the FDI system. The sensor FDI system is applied to a commercial aircraft engine simulation, and its performance is evaluated at multiple power settings at a cruise operating point using various fault scenarios.
\end{abstract}

\section{INTRODUCTION}

In-flight sensor fault detection and isolation (FDI) is critical to maintaining reliable engine operation during flight. The propulsion system is operated at demanded conditions by the aircraft engine control system which computes control commands based on sensor measurements. Any undetected sensor faults, therefore, may cause the control system to drive the engine into an undesirable operating condition. If a sensor fails, it is crucial to detect and isolate the fault as soon as possible so that such scenarios can be avoided. A sensor FDI system which is capable of doing so with high reliability is indispensable for flight safety enhancement. A challenging issue in developing reliable sensor FDI systems is to make them robust to other faults, besides sensor faults, that can occur during flight. Engine component performance can degrade gradually due to usage, and abruptly due to fault events such as foreign or domestic object damage. Likewise, errors can exist between the commanded and actual actuator positions. Such anomalies result in shifts in sensed engine variables from their nominal values. Therefore, a sensor FDI system which is developed without accounting for possible component or actuator faults may result in false alarms, missed detections, or misclassifications when such faults do occur.

An approach to in-flight sensor FDI for aircraft propulsion system was addressed by Merrill et al. [1] through the utilization of a bank of Kalman filters. In this approach, each Kalman filter is designed based on a specific hypothesis (such as the failure of a specific sensor). When a single sensor fails, only the one Kalman filter with the correct fault hypothesis can maintain low residual values, indicating that the specific sensor has failed. This work was later extended by Kobayashi et al. [2] to account for not only sensor faults, but also actuator and component faults. This approach exhibited improved robustness of the FDI system; however, the number of component fault events that could be accounted for by the FDI system was limited to the number of available sensors. In spite of such limitations, the previous research [2] revealed potential areas for further improvement of an FDI system. In this paper, lessons learned from the earlier work are incorporated to enhance the bank of Kalman filters for an in-flight sensor FDI application. The objectives of sensor FDI are as follows:

- Avoid missed detections: When a single sensor is faulty, it must be correctly detected and isolated.

- Avoid false alarms: Non-fault-related factors that exist in the real environment, such as sensor noise and modeling uncertainty, should not be diagnosed as a sensor fault.

- Avoid misclassifications: Component or actuator faults should not be misclassified as a sensor fault.

In this paper, a sensor FDI system is developed and applied to a nonlinear simulation of a commercial aircraft gas turbine engine. The FDI system performance is evaluated at multiple power settings at a cruise operating point using various fault scenarios. 


\section{NOMENCLATURE}

$\begin{array}{ll}\text { BST } & \text { Booster } \\ \text { FAN } & \text { Fan } \\ \text { FDI } & \text { Fault detection and isolation } \\ \text { HPC } & \text { High-pressure compressor } \\ \text { HPT } & \text { High-pressure turbine } \\ \text { LPT } & \text { Low-pressure turbine } \\ \text { P25 } & \text { HPC inlet pressure } \\ \text { PLA } & \text { Power lever angle } \\ \text { PS3 } & \text { Combustor inlet static pressure } \\ \text { T25 } & \text { HPC inlet temperature } \\ \text { T3 } & \text { Combustor inlet temperature } \\ \text { T49 } & \text { LPT inlet temperature } \\ \text { TMHS23 } & \text { BST metal temperature } \\ \text { TMHS3 } & \text { HPC metal temperature } \\ \text { TMHS41 } & \text { HPT nozzle metal temperature } \\ \text { TMHS42 } & \text { HPT metal temperature } \\ \text { TMHS5 } & \text { LPT metal temperature } \\ \text { TMHSBC } & \text { Combustor case metal temperature } \\ \text { TMHSBL } & \text { Combustor liner metal temperature } \\ \text { VBV } & \text { Variable bleed valve } \\ \text { VSV } & \text { Variable stator vane } \\ \text { WF36 } & \text { Fuel flow } \\ \text { XN12 } & \text { Low-pressure spool speed, measured } \\ \text { XN25 } & \text { High-pressure spool speed, measured } \\ \text { XNH } & \text { High-pressure spool speed, state variable } \\ \text { XNL } & \text { Low-pressure spool speed, state variable }\end{array}$

\section{DEVELOPMENT OF ROBUST SENSOR FAULT DETECTION AND ISOLATION SYSTEM}

The problem approach to sensor FDI is similar to that of reference [2]. A depiction of the propulsion system with the sensor FDI system is shown in fig. 1. During flight, the sensors, actuators, and engine components are susceptible to failure. The sensor and actuator faults dealt with in this paper are "soft" failures. Soft failures are defined as inconsistencies between true and measured sensor values (or true and commanded actuator position) that are relatively small in magnitude and thus difficult to detect, whereas "hard" failures are large in magnitude and thus more readily detectable. Soft failures can take different forms such as a fixed scale factor, a fixed bias, a drift, or intermittent spikes. Among these, only the fixed bias is considered in this paper for FDI evaluation purposes, although the proposed FDI approach is applicable to other soft failure types as well. Engine component faults are modeled in the simulation environment by abruptly shifting the health

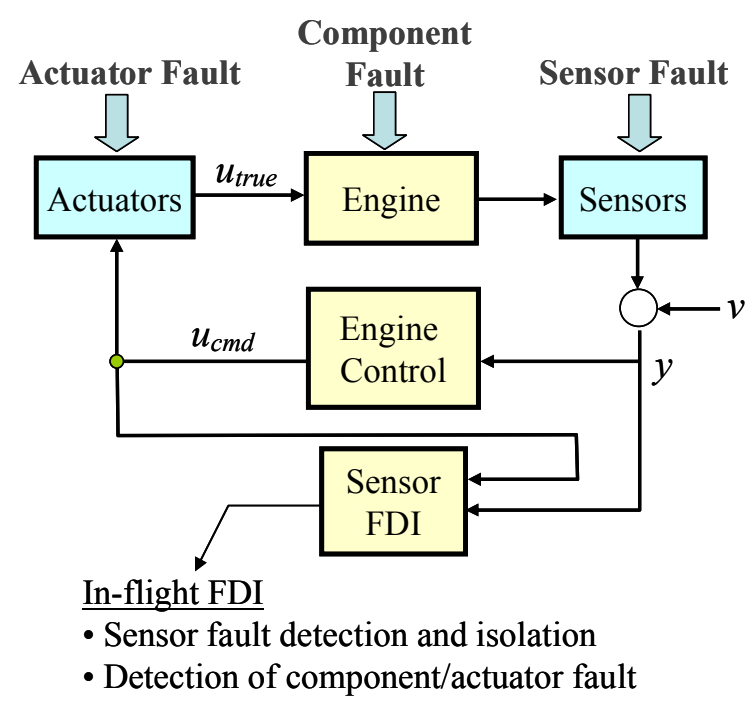

Figure 1. Propulsion System with Sensor Fault
Detection and Isolation System

parameters which indicate component performance deviations from a reference base point.

The FDI system uses two sets of input signals: sensor measurements and control commands. Those sensors used by the control system are also used by the FDI system for monitoring purposes. Given these two sets of input signals, the FDI system seeks to detect and isolate any faulty sensors. The approach to sensor FDI is based on the utilization of a bank of Kalman filters, where each filter is designed with a unique hypothesis to monitor a specific sensor. In addition to sensors, components and actuators may also fail during flight. Therefore, it is necessary to make the FDI system robust to these faults so that misclassifications of component and actuator faults as sensor faults do not occur. This issue is addressed by designing one additional Kalman filter which assumes that components and actuators may be faulty. When the propulsion system experiences a sensor fault or component/actuator faults, only the one Kalman filter with the correct hypothesis is able to maintain accurate estimation performance. Consequently, the detection and isolation of sensor faults or the detection of component/actuator faults can be achieved. As can be seen in fig. 1, the outputs of the FDI system are not integrated with the control system in the present work. The integration of these systems for fault accommodation purposes will be pursued in future work. In the following sections, the design approach for the FDI system is discussed in detail. 


\section{Kalman Filter Design for Sensor Fault Detection}

The Kalman filter design approach is based on the linear model representation of a plant. The linearized engine model under consideration is represented by the following state space equations:

$$
\begin{aligned}
& \dot{x}=A\left(x-x_{s s}\right)+L\left(h-h_{r e f}\right)+B\left(u_{c m d}-u_{s s}\right)+B b \\
& y-y_{s s}=C\left(x-x_{s s}\right)+M\left(h-h_{r e f}\right)+D\left(u_{c m d}-u_{s s}\right)+D b+v
\end{aligned}
$$

where the vectors $x, h, u_{c m d}$ represent state variables, health parameters, and control commands, respectively. The subscript "ss" indicates the steady-state point (or the base point at which the model was linearized). The vector $h_{r e f}$ represents a reference health condition. The sensor measurement vector, $y$, is corrupted by sensor noise $v$. The vector $b$ represents the bias in the actuation system; it is zero when there is no actuator bias. The health parameter and bias vectors are unknown inputs to the system that affect engine operation. The matrices $A, B, C$, $D, L$, and $M$ have appropriate dimensions.

For sensor fault detection, $m$ Kalman filters are designed where $m$ is the number of sensors being monitored. Each Kalman filter estimates the state vector using a unique set of $(m-1)$ sensors. The sensor which is not used by a particular filter is assumed to be the potentially faulty one (fault hypothesis) and thus monitored by that filter. For instance, the $i^{\text {th }}$ filter uses the sensor subset $y^{i}$ that excludes the $i^{\text {th }}$ sensor, where $i$ is an integer from 1 to $m$. When the $i^{\text {th }}$ sensor is faulty, all Kalman filters use faulty information except for the $i^{\text {th }}$ filter. Consequently, the $i^{\text {th }}$ filter is able to accurately estimate the state vector from fault-free sensor measurements, whereas the estimates of the remaining filters are distorted by the faulty sensor measurement. The Kalman filter equation that monitors the $i^{\text {th }}$ sensor is given as follows:

$$
\begin{aligned}
& \dot{\hat{x}}=A\left(\hat{x}-x_{s s}\right)+B\left(u_{c m d}-u_{s s}\right)+K^{i}\left(y^{i}-\hat{y}^{i}\right) \\
& \hat{y}^{i}-y_{s s}^{i}=C^{i}\left(\hat{x}-x_{s s}\right)+D^{i}\left(u_{c m d}-u_{s s}\right)
\end{aligned}
$$

where $\hat{x}$ and $\hat{y}^{i}$ are the estimates of the state vector and the $i^{\text {th }}$ sensor-subset vector, respectively. The matrices $C^{i}$ and $D^{i}$ are a subset of $C$ and $D$, respectively, with the $i^{\text {th }}$ row deleted, and $K^{i}$ is a Kalman gain matrix corresponding to the matrix pair $\left(A, C^{i}\right)$. In order for the Kalman filter to converge, the matrix pair $\left(A, C^{i}\right)$ must be observable.

The accuracy of the estimated state variables is indicated by a weighted sum of squared residuals (WSSR) which is computed as follows:

$$
\operatorname{WSSR}^{i}=\left(y^{i}-\hat{y}^{i}\right)^{T}\left(\Sigma^{i}\right)^{-1}\left(y^{i}-\hat{y}^{i}\right)
$$

where

$$
\Sigma^{i}=\operatorname{diag}\left[\sigma^{i}\right]^{2}
$$

The vector $\sigma^{i}$ represents the standard deviation of the $i^{\text {th }}$ sensor-subset. The square matrix $\Sigma^{i}$ normalizes the residual vector $\left(y^{i}-\hat{y}^{i}\right)$. The value of the fault indicator signal, WSSR, increases if the sensor subset used by a Kalman filter contains a faulty measurement. In order to detect an anomaly in the sensor set, the fault indicator signals are compared against pre-established detection thresholds. If all fault indicator signals except one exceed the threshold, it indicates that the Kalman filter whose fault indicator signal did not exceed the threshold is the one with the correct fault hypothesis. Consequently, this filter is isolated, and the sensor excluded by this filter is identified as the faulty one.

It should be noted that the Kalman filter in eq. (2) does not account for the influence of health parameters or actuator biases that appear in eq. (1). Therefore, any deviations of these parameters from the design point can cause an increase in the values of the fault indicator signals. Depending on their magnitude, such deviations may induce a fault misclassification scenario where all fault indicator signals except one exceed the detection threshold. To avoid such scenarios, additional features that account for health parameter and actuator bias deviations must be built into the FDI system. For the health parameters, two possible deviation types need to be considered: 1) gradual degradation due to aging, and 2) abrupt degradation due to component faults. An approach to deal with the gradual degradation was discussed in reference [2]. That is, estimate all health parameters once per a number of flights using groundbased trend monitoring techniques [3,4,5], update the reference health condition $\left(h_{r e f}\right)$ and the linear engine model in eq. (1), and then update the Kalman filter. As long as this updated reference health condition remains close enough to the actual condition (which continues to degrade with time), the interference of the gradual degradation on the Kalman filters designed through eq. (2) will remain small. Abrupt degradation $\left(\Delta h=h-h_{r e f}\right.$ in eq. 1$)$ due to component faults or actuator bias needs to be handled by other means. The approach taken in this paper is to design another Kalman filter which assumes that components and/or actuators may be faulty. If this filter is able to maintain low residual values in the case of component and/or actuator faults, misclassifications of these faults as a sensor fault may be avoided. The design of this additional Kalman filter is discussed in the following section.

\section{Kalman Filter Design for Component and Actuator Fault Detection}

Ideally, a Kalman filter which is capable of accurately estimating all health parameters is desirable. Such a filter would be able to maintain accurate sensor estimation (and thus low residuals) even in the presence of component faults. However, the number of health parameters that can be estimated is limited to the number of available sensors [6]. 
Aircraft engines have a limited number of sensors which is, in general, less than the number of health parameters. Therefore, estimating all health parameters is not realistic. An alternative approach, which can meet the aforementioned objective while using a limited number of sensors, is to estimate a subset of health parameters. In reference [2], it was observed that the Kalman filter, designed with a subset of health parameters, could retain accurate estimation of sensor outputs when applied to a "degraded" engine simulation. The accuracy of the estimated health parameters, however, was poor as the Kalman filter attributed the steady-state mismatch caused by health degradation to the subset of health parameters being estimated. Therefore, the estimated health parameters no longer indicate the actual health condition, but instead, they are "tuning" parameters that the Kalman filter can use to generate accurate sensor estimates. This concept of "tuning" is applied to the design of a Kalman filter in this section. The idea is to use tuning parameters (a subset of health parameters) with which the Kalman filter can maintain good sensor estimation performance no matter what combination of health parameters is shifted from their reference point. The Kalman filter equation that incorporates the tuning parameters is given as follows:

$$
\begin{aligned}
& \dot{\hat{x}}_{\text {aug }}=\left[\begin{array}{cc}
A & L_{d} \\
0 & 0
\end{array}\right]\left(\hat{x}_{\text {aug }}-\bar{x}_{s s}\right)+\left[\begin{array}{l}
B \\
0
\end{array}\right]\left(u_{c m d}-u_{s s}\right)+K(y-\hat{y}) \\
& \hat{y}-y_{s s}=\left[\begin{array}{ll}
C & M_{d}
\end{array}\right]\left(\hat{x}_{\text {aug }}-\bar{x}_{s s}\right)+D\left(u_{c m d}-u_{s s}\right)
\end{aligned}
$$

where

$$
\hat{x}_{\text {aug }}=\left[\begin{array}{l}
\hat{x} \\
d
\end{array}\right], \bar{x}_{s s}=\left[\begin{array}{c}
x_{s s} \\
0
\end{array}\right]
$$

The vector $d$ contains the tuning parameters. The matrices $L_{d}$ and $M_{d}$ are selected columns of $L$ and $M$, respectively, and their columns correspond to the tuning parameters. As discussed earlier, all health parameters gradually deviate from the healthy baseline. This deviation is called "baseline degradation" ( $h_{r e f}$ in eq. 1) and can be tracked by ground-based trend monitoring techniques once per a number of flights. As the gradual degradation progresses, all Kalman filters need to be updated based on the estimated baseline degradation so that the Kalman filters will operate within the linear range of a degraded engine. The tuning parameters are the deviation values from this updated reference point.

Similar to the Kalman filters designed for sensor fault detection, the accuracy of the estimated sensor measurements is indicated by a weighted sum of squared residuals (WSSR) which is computed as follows:

It is desirable to update both state-space matrices and steady-state points. If this is not achievable, then at least the steady-state points must be updated, while maintaining the state-space matrices obtained at the healthy baseline condition.

$$
\operatorname{WSSR}=(y-\hat{y})^{T}(\Sigma)^{-1}(y-\hat{y})
$$

where

$$
\Sigma=\operatorname{diag}[\sigma]^{2}
$$

The vector $\sigma$ represents the standard deviation of the sensor set. It should be noted that this filter uses all sensors of the given sensor suite. The assumption of this filter is that all sensors are healthy and that components are potentially faulty (fault hypothesis).

The fault indicator signal of this filter must meet two requirements: 1) it must remain small in the case of component faults and 2) it must increase in the case of a sensor fault. These two conditions are required to indicate whether the fault hypothesis of this filter is correct or incorrect. It was found that this WSSR could meet the first condition, but not the second one. In the case of a sensor fault, the WSSR could remain small depending on which sensor is faulty. After some investigation, it was found that, whenever the WSSR remains small in the presence of a faulty sensor, the sensor fault is attributed to the engine internal condition: the tuning parameters. In other words, the Kalman filter tries to "explain" a sensor fault by shifting the tuning parameters. If it is successful in doing so, the value of WSSR remains small.

To address this shortcoming, another fault indicator signal is used. This signal, a weighted sum of squared tuners (WSST), is computed as follows:

$$
W S S T=W_{d}\left(d^{T} d\right)
$$

where $W_{d}$ is a designer selected weighting factor. Regardless of the fault type, the value of WSST increases when a fault occurs. However, the following two conditions were observed: 1) the increase in WSST is generally small in the component fault case, and 2) the increase in WSST becomes excessively large whenever this Kalman filter maintains a low WSSR value in the presence of a faulty sensor. Based on these observations, the two fault indicator signals (WSSR and WSST) are used in combination to indicate whether the fault hypothesis of this filter is correct or incorrect. If both signals remain below their detection thresholds, the fault hypothesis is correct, i.e., component faults may exist but all sensors are healthy. If at least one of them exceeds the detection threshold, the fault hypothesis is incorrect, and thus a sensor fault is believed to exist. Through this approach, sensor and component faults can be distinguished. It should be noted that as the magnitude of a component fault increases, the value of WSST increases and eventually exceeds the detection threshold. By the time this happens, it is expected that each fault indicator signal generated for sensor fault detection would already have exceeded its threshold so that misclassifications of component faults as a sensor fault will be avoided.

So far, only the component fault case has been discussed in this section. Actuator faults can be handled by either augmenting the tuning parameter vector in eq. (4) with the 
actuator bias term in eq. (1) or designing single Kalman filters for each of the actuators as was done in reference [2]. However, a different approach is taken in this paper. When an actuator is biased, it causes a measurement shift in multiple sensors, similar to the component fault case. The Kalman filter designed with tuning parameters can handle such multiple measurement shifts and, therefore, is considered to have some robustness to actuator faults as well, i.e., the two fault indicator signals will remain small when actuators are faulty. Therefore, the Kalman filter with tuning parameters is used to detect both component and actuator faults. If this filter is not robust to actuator faults, then the designer must take one of the aforementioned approaches to meet design objectives.

It should be noted that, when the Kalman filter with tuning parameters is isolated from the rest of the filters, the specific component(s) and/or actuator(s) which are faulty are not identified. For further diagnosis of the component and actuator faults, another set of Kalman filters, each designed for a specific fault event (such as foreign object damage, domestic object damage, fuel system failure, etc.), may be used. Since it is already known that a fault exists, a detection threshold is not needed. Instead, by ranking the likelihood of plausible faults based on the Kalman filter estimation accuracy, the possibility of misclassifications may be reduced. This process was demonstrated by Volponi et al. [7], and a high success rate was exhibited.

\section{Overall Sensor FDI Architecture}

The overall architecture of the sensor FDI system is shown in fig. 2. The FDI system is composed of a bank of $(m+1)$ Kalman filters where $m$ is the number of sensors being monitored. Kalman filters 1 through $m$ are used to detect sensor faults while the $(m+1)^{s t}$ Kalman filter is used for the detection of component/actuator faults. With this bank of Kalman filters, the following assumptions are made:

- Only one sensor may fail at a time.

- Multiple components and actuators may fail at a time.

- Only one of the above two types of failures may occur at a time.

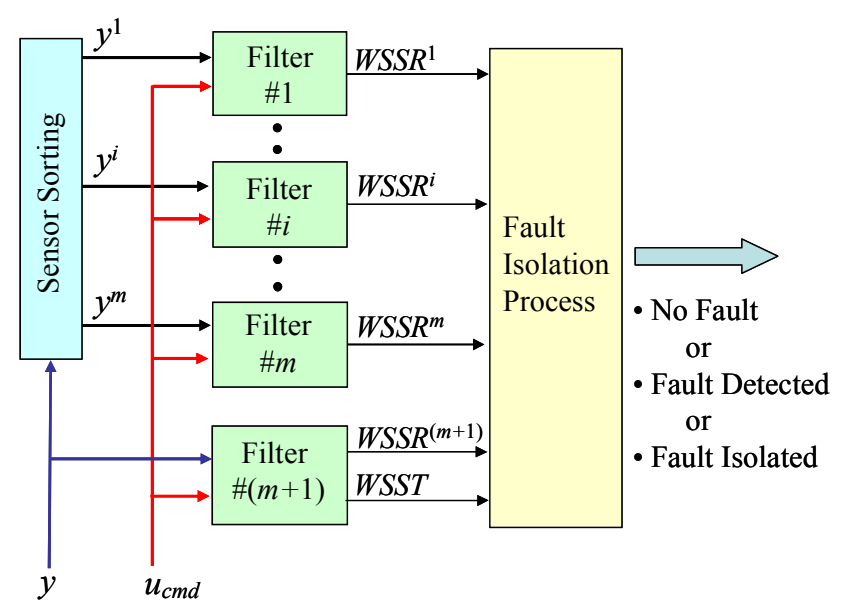

Figure 2. Architecture of the Sensor FDI System

In the fault isolation process, the fault indicator signal generated by each Kalman filter is compared against a predefined detection threshold. If a fault indicator signal exceeds the threshold, it indicates that the corresponding Kalman filter is using an incorrect fault hypothesis. The Kalman filter $\#(m+1)$ generates two fault indicator signals, and at least one of them must exceed the threshold to indicate that its fault hypothesis is incorrect.

Table 1 summarizes the fault isolation process. There are eight possible scenarios, as enumerated in table 1 , that the fault isolation process may encounter. When sensors, actuators, and components are all nominal, all fault indicator signals will remain below their thresholds, indicating that no fault exists in the system (scenario 1). When a fault occurs, the value of each fault indicator signal except for the one with the correct hypothesis will increase. The increased amount will vary for each fault indicator signal as each filter has a different response or sensitivity to a particular fault. Depending on the type and severity of the fault, some fault indicator signals may exceed their thresholds while others may remain below. If at least one

Table 1. Summary of Fault Isolation Process

\begin{tabular}{|c|c|c|c|}
\hline & & \multicolumn{2}{|c|}{$\begin{array}{c}W S S R^{(m+1)} \text { and WSST for Kalman Filter \#(m+1) } \\
\text { (Component and/or Actuator Fault Hypothesis Filter) }\end{array}$} \\
\hline & & $\begin{array}{l}\text { Both remain below } \\
\text { threshold }\end{array}$ & $\begin{array}{l}\text { Either one or both exceed } \\
\text { threshold }\end{array}$ \\
\hline \multirow{4}{*}{$\begin{array}{l}W_{S S R}^{i} \\
\text { for Kalman } \\
\text { filters \#1 \#m } \\
\text { (Sensor Fault } \\
\text { Hypothesis } \\
\text { Filters) }\end{array}$} & All WSSRs remain below threshold & 1) No fault exists & $\begin{array}{l}\text { 2) Detection of fault } \\
\text { (no isolation) }\end{array}$ \\
\hline & $\begin{array}{l}\text { At least one WSSR exceeds } \\
\text { threshold and at least two WSSRs } \\
\text { remain below threshold }\end{array}$ & $\begin{array}{l}\text { 3) Detection of fault } \\
\text { (no isolation) }\end{array}$ & $\begin{array}{l}\text { 4) Detection of fault } \\
\text { (no isolation) }\end{array}$ \\
\hline & All but one WSSR exceed threshold & $\begin{array}{l}\text { 5) Detection of fault } \\
\text { (no isolation) }\end{array}$ & $\begin{array}{l}\text { 6) Detection and isolation } \\
\text { of sensor fault }\end{array}$ \\
\hline & All WSSRs exceed threshold & $\begin{array}{l}\text { 7) Detection of } \\
\text { component/actuator fault }\end{array}$ & $\begin{array}{l}\text { 8) Detection of large } \\
\text { component/actuator fault }\end{array}$ \\
\hline
\end{tabular}


fault indicator signal exceeds its threshold, the fault isolation process declares that a fault was detected. However, the isolation of a fault can not be achieved as long as at least two Kalman filters do not have a threshold violation. Scenarios 2 through 5 represent these cases where a fault can be detected but not isolated. When a threshold violation occurs for all Kalman filters except one, then this single Kalman filter is isolated from the rest, and the fault hypothesis used by this filter reveals the identity of the fault. Thus, the isolation of a sensor fault is achieved in scenario 6 , and the detection of a component/actuator fault is achieved in scenario 7. Finally, as discussed earlier, when a threshold violation occurs for all Kalman filters, the fault isolation process declares that a large component/actuator fault has occurred (scenario 8).

\section{APPLICATION OF FDI METHODOLOGY TO AN AIRCRAFT ENGINE SIMULATION}

In this section, the FDI design methodology is applied to an aircraft engine simulation. A description of the engine simulation is given first. From the engine simulation, piecewise linear models are generated along the steady-state power setting line at a cruise condition. Based on these linear models, the piecewise Kalman filter model is developed in order to cover multiple power settings.

\section{Engine Model}

The engine model used in this paper is a nonlinear simulation of an advanced high-bypass turbofan engine. This engine is constructed as a Component Level Model (CLM), which assembles the following five major components of an aircraft engine: Fan (FAN), Booster (BST), High-Pressure Compressor (HPC), High-Pressure Turbine (HPT), and LowPressure Turbine (LPT). The health parameters, which represent the component performance deterioration, are adjustments to efficiency and flow capacity scalars of the above five components. The current version of the simulation does not have health parameters for the combustor. The engine state variables, health parameters, actuation variables, and sensor measurements are shown in table 2.

The outputs of the seven sensors in table 2 are fed into the digital engine control unit. At the cruise operating condition evaluated in this study, the power lever angle (PLA) value is

Table 2. State, Health, Actuator, and Sensor Variables

\begin{tabular}{|l||l|}
\hline State Variables & $\begin{array}{l}\text { XNL, XNH, TMHS23, TMHS3, TMHSBL } \\
\text { TMHSBC, TMHS41, TMHS42, TMHS5 }\end{array}$ \\
\hline Health & FAN efficiency, FAN flow capacity \\
Parameters & BST efficiency, BST flow capacity \\
& HPC efficiency, HPC flow capacity \\
& HPT efficiency, HPT flow capacity \\
& LPT efficiency, LPT flow capacity \\
\hline Actuators & WF36, VBV, VSV \\
\hline Sensors & XN12, XN25, P25, T25, PS3, T3, T49 \\
\hline
\end{tabular}

converted to the desired corrected low-pressure spool speed (an indicator of thrust). The control system adjusts three actuation variables to cause the corrected measured low-pressure spool speed value to match the commanded value. PLA varies from 38 to 72 degrees.

The standard deviations of the sensor noise used in this paper are shown in table 3 . The values are given in percent of the steady-state values at the maximum power setting $(\mathrm{PLA}=72)$.

Table 3. Sensor Noise Standard Deviation in \% of the
Trim Values at Maximum Power
\begin{tabular}{|c|c|}
\hline Sensor & $\sigma$ \\
\hline \hline XN12 & 0.25 \\
\hline XN25 & 0.25 \\
\hline P 25 & 0.50 \\
\hline T25 & 0.75 \\
\hline PS3 & 0.50 \\
\hline T3 & 0.75 \\
\hline T 49 & 0.75 \\
\hline
\end{tabular}

\section{Piecewise Kalman Filter Model}

At the selected cruise condition, piecewise linear engine models are generated along the steady-state power setting line where PLA varies from 38 to 72 degrees. A linear engine model is composed of trim values and state space matrices. For each of these linear models, a Kalman gain is computed. Then, the piecewise Kalman filter model is developed by linking the piecewise linear models and the corresponding Kalman gains. The architecture of the piecewise Kalman filter model is shown in fig. 3.

The piecewise Kalman filter model is composed of the steady-state (base-point) model, state-space matrices, and Kalman gains. The steady-state model captures nonlinear engine characteristics along the power setting line, while the state-space matrices (dynamic model) capture off-nominal engine behavior due to perturbations from the steady-state line. These three elements of the Kalman filter model are saved in table lookup form. For a given set of two input signals $\left(u_{c m d}, y\right)$, the steady-state values, the state-space matrices, and a Kalman gain constitute the Kalman filter equation, by which the state variables and sensor outputs are estimated. As PLA moves from one point to another, those elements saved in the lookup table are interpolated linearly based on a scheduling parameter. In the current model, the estimated low-pressure spool speed (XN12) is used as the scheduling parameter. It should be noted that the scheduling parameter can be a function of multiple parameters as in references [1,8]. More detailed discussion regarding the piecewise linear state variable model can be found in references [8,9].

By using the architecture of fig. 3, a piecewise Kalman filter model is built for each fault hypothesis (eqs. 2 and 4), and a bank of Kalman filters is formed as shown in fig. 2. The FDI system is now able to cover the full PLA range at a fixed 


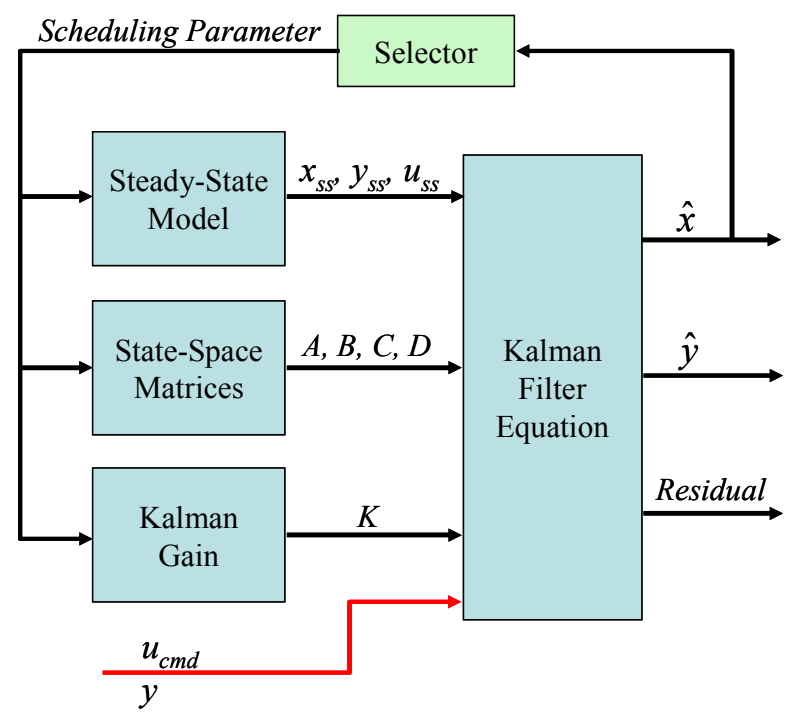

\section{Figure 3. Architecture of Piecewise Kalman Filter Model}

ambient condition of the selected cruise point. In order to expand the range of ambient conditions over which the FDI system can operate, the parameters of the Kalman filters must be corrected based on inlet condition, however, this additional step is not pursued in this paper.

\section{Selection of Tuning Parameters}

The selection of the tuning parameters for designing the $(m+1)^{s t}$ Kalman filter is critical in order to achieve overall sensor FDI performance at an acceptable level. It is desirable to have some optimal selection methods; however, the tuning parameters used in this paper were selected by trial and error. The selected tuning parameters are: FAN flow capacity, BST flow capacity, HPC efficiency, HPC flow capacity, HPT flow capacity, and LPT flow capacity. With these tuning parameters, the Kalman filter is able to accurately estimate sensor outputs even if all 10 health parameters are shifted from a reference point. Again, it should be remembered that the tuning parameters do not indicate the actual health condition although they are selected from the health parameters.

\section{Modifications to the FDI System}

During the preliminary evaluation of the FDI system, it was found that the Kalman filter design approach for the fault detection of the XN25 and T25 sensors had to be modified. When either of these sensors is biased, the control system generates a large off-nominal variable stator vane (VSV) command. As discussed earlier, piecewise linear models are generated along the steady-state power setting line. Any control input deviation from this steady-state line is the delta input to the linear models. Under normal fault-free engine operation, any control input deltas remain relatively small, and therefore the linear models are valid to describe the off-nominal engine behavior. However, when one of the aforementioned two sensors is biased, the engine operates at a condition where the steady-state VSV command is significantly shifted from its nominal value. This large shift, used as an input to linear model, exceeds the linear range and gives the appearance that VSV is biased. The assumption of the bank of Kalman filters for sensor FDI is that at most one sensor is faulty while the others, including the actuators, remain at their nominal condition. Therefore, with the large shift in the VSV command input, the Kalman filters designed for monitoring XN25 and T25 are not able to accurately estimate state variables and sensor outputs, and consequently a large fault indicator signal is generated. In the meantime, the Kalman filter designed with tuning parameters is able to generate low fault indicator signals since this filter can handle the shifts in multiple parameters. Thus, without modifications, the FDI system will misclassify $\mathrm{XN} 25$ or T25 sensor faults as the component/actuator fault case.

To address this problem, the Kalman filters for the XN25 and T25 sensors are designed based on the augmented state vector which is composed of the state vector and the VSV bias term. This approach, which was used in reference [2], allows the Kalman filters to estimate a bias in VSV. When a large offnominal steady-state VSV value is commanded, the Kalman filters attribute this large input to the estimated VSV bias. With this modification, the effect of a large command input that corrupts the estimation of these Kalman filters is reduced, and therefore the sensor outputs are accurately estimated. The problem of a large off-nominal shift in the VSV command is specific to the control system used in the current study. If a different control design is employed, this problem may not be encountered; instead, new challenges may appear.

\section{PERFORMANCE EVALUATION OF THE SENSOR FDI SYSTEM}

In this section, the FDI system is evaluated at three PLA settings: 50, 60 and 68 degrees. As discussed earlier, the three objectives of sensor FDI are to avoid 1) missed detections, 2) false alarms, and 3) misclassifications. The evaluation is based on each of these objective categories. Additionally, the robustness of the FDI system is evaluated.

\section{Evaluation 1: Missed Detections}

When a single sensor is faulty, it must be correctly detected and isolated. If this objective is not achieved, it is considered that the FDI system missed the detection of the sensor fault. To assess the missed detection rate generated by the FDI system, it is desirable to have design specifications which define the bias magnitude at which sensors transition from "nominal" to "faulty" operation. Since such information is not available in this study, the minimum sensor bias that the proposed FDI system can isolate is determined for each of the sensors. If design specifications are available, the FDI system, or specifically the detection thresholds, may be adjusted to meet a desired performance level. 
Table 4 shows the minimum positive bias in each sensor that could be isolated by the FDI system at the three power settings considered. The numbers are given in percent of the steady-state values at the maximum power setting (PLA=72). All sensor biases of these magnitudes were isolated correctly. The magnitude of the minimum isolated bias varies with sensor type and also with power setting. This variation in the magnitude depends on how easily the "correct" Kalman filter can be isolated from the rest of the filters. For most of the test cases, the fault indicator signal which exceeded the threshold last (the correct one must remain below the threshold) is the one corresponding to the Kalman filter with tuning parameters. Therefore, overall sensor isolation performance of the FDI system depends not only on the sensor suite but also the selection of tuning parameters. The worst case, or the largest minimum bias value that could be isolated, is the $6.7 \%$ PS3 sensor bias. If the isolation of smaller magnitude faults is desired, the detection thresholds must be set lower. However, this adjustment may result in increased false alarms and misclassifications.

When PLA is moved beyond the value of 68 degrees, it becomes very difficult to isolate XN25 sensor bias. As mentioned, bias in this sensor causes a large off-nominal shift in the steady-state VSV command input. Similarly, the offnominal steady-state shift in the WF36 command input increases as PLA increases. When PLA exceeds 68, this offnominal WF36 shift becomes too large for the linear model to handle. As a result, XN25 sensor bias is diagnosed as a component/actuator fault by the FDI system. This problem may be solved by augmenting the state vector with a WF36 bias term as was done for the VSV input. However, this further step has not been taken in this work.

Table 4. Minimum Positive Bias Isolated by the Sensor FDI System (\% of Steady-State Value at Maximum Power)

\begin{tabular}{|c|c|c|c|}
\hline & PLA=50 & PLA=60 & PLA=68 \\
\hline XN12 & 1.6 & 1.9 & 2.1 \\
\hline XN25 & 4.7 & 4.0 & 3.4 \\
\hline P25 & 2.9 & 3.5 & 5.0 \\
\hline T25 & 2.1 & 2.0 & 2.0 \\
\hline PS3 & 3.2 & 5.1 & 6.7 \\
\hline T3 & 2.8 & 3.5 & 4.1 \\
\hline T49 & 2.3 & 2.9 & 3.2 \\
\hline
\end{tabular}

\section{Evaluation 2: False Alarms}

When the FDI system is applied to a real engine, non-faultrelated factors which exist in the real environment, such as sensor noise and modeling uncertainty, should not be diagnosed as a sensor fault. If this happens, the FDI system will have generated a false alarm. Since the Kalman filter design approach accounts for these non-fault-related factors to some degree, the estimator should handle them well as long as they do not deviate significantly from their assumed values.

In the previous evaluation step, the FDI system was applied to the nonlinear engine simulation at three different power settings. When there was no sensor bias, no false alarm was generated. This means that the Kalman filters are able to handle the given sensor noise (table 3 ) and the model mismatch that exists between the nonlinear engine simulation and its linear representation. In this section, the robustness of the FDI system to sensor noise and modeling uncertainty is evaluated by varying the magnitude of these factors.

At the steady-state condition of the three power settings used in the previous section, either the sensor noise level or the model uncertainty level is increased. By increasing these factors, the FDI system may eventually generate a false alarm (only one fault indicator signal remaining below the detection threshold). In this study, however, the level of sensor noise and model uncertainty is increased up to the initial point of fault detection where the threshold is just exceeded by at least one fault indicator signal. If the FDI system can tolerate a large magnitude increase in these factors, it is considered that the likelihood of generating false alarms is very small.

In the simulation, the sensor noise is increased by multiplying the standard deviation (table 3 ) by a scale factor. Model uncertainty is introduced by shifting all 10 health parameters of the nonlinear engine simulation by the same amount from the healthy baseline. Since the FDI system was designed based on a "healthy" engine, the outputs of the "degraded" nonlinear engine simulation deviate from the design point of the FDI system. Table 5 shows the level of sensor noise scale factor and model uncertainty (steady-state model mismatch) that the FDI system can tolerate, i.e., all fault indicator signals remain below the threshold. The noise scale factor was increased by $1 \%$ increments while the steady-state model mismatch was increased by $0.1 \%$ increments to obtain these results. When the level of either one of these two factors is increased, the other was kept at the nominal design condition.

As the noise scale factor was increased, the values of all WSSR signals increased even though the Kalman filters could maintain good estimation accuracy of sensor outputs. This increase is due to the fact that the normalization factor $(\Sigma$ in eqs. 3 and 5) used to generate WSSR is based on the assumed noise intensity. Noise that exists in the real environment is never certain. Therefore, the detection threshold has been selected to account for the uncertainty in noise statistics. The FDI system can tolerate, at worst, a 9\% (at PLA=50) noise increase. If this value is considered too small, then the detection threshold must be increased accordingly.

Similarly, the fault indicator signals increase as the level of steady-state model mismatch is increased. Model mismatch causes a shift in all sensor measurements from the reference point, as if small biases were injected into all sensors. Since the Kalman filter assumes that the sensor outputs are corrupted only by white noise, it is not able to maintain good estimation accuracy when model mismatch is present. The variation in fault indicator signals due to model mismatch must be accounted for in threshold selection. The FDI system can tolerate, at worst, a $0.3 \%$ (at PLA=68) shift in all health parameters. Again, if this value is considered too small, then the detection threshold must be increased accordingly. 
Table 5. Non-Fault-Related Factors Tolerated by the FDI System

\begin{tabular}{|c|c|c|c|}
\hline & PLA=50 & PLA=60 & PLA=68 \\
\hline $\begin{array}{c}\text { Noise } \\
\text { Factor }\end{array}$ & $9 \%$ & $11 \%$ & $13 \%$ \\
\hline $\begin{array}{c}\text { Model } \\
\text { Mismatch }\end{array}$ & $0.7 \%$ & $0.4 \%$ & $0.3 \%$ \\
\hline
\end{tabular}

\section{Evaluation 3: Misclassifications}

A misclassification is an event where the FDI system correctly detects a fault that exists in the engine but classifies it as the wrong fault. For example, when an anomaly other than a sensor fault occurs in the aircraft engine, the sensor FDI system should not classify it as a sensor fault. If it does, it is considered that the FDI system misclassified the fault. Such anomalies can occur to engine components during flight due to fault events such as foreign or domestic object damage. Anomalies can also exist in actuators due to mechanical or electrical failure in the actuation systems. In order to avoid misclassification, the FDI system contains one additional Kalman filter designed with tuning parameters as discussed earlier. When components or actuators are faulty, the two fault indicator signals (WSSR and WSST) of this filter should not exceed the threshold. If this can be achieved, the FDI system will not misclassify component or actuator faults as a sensor fault. In this section, the FDI system is evaluated as to whether it can avoid misclassifications of component and actuator faults.

Table 6 shows the component/actuator fault scenarios used to evaluate the FDI system at the three power settings (PLA $=50,60,68)$. For each engine component, both efficiency

\section{Table 6. Component and Actuator Fault Scenarios for the FDI Performance Evaluation}

\begin{tabular}{|l|l|l|l|}
\hline & & Delta Range & \# of Cases \\
\hline $\begin{array}{l}\text { Single } \\
\text { Component }\end{array}$ Fault & FST & {$[1 \%, 4 \%]$} & 50 \\
& HPC & {$[1 \%, 4 \%]$} & 50 \\
& HPT & {$[1 \%, 4 \%]$} & 50 \\
\hline $\begin{array}{l}\text { Multiple } \\
\text { Component }\end{array}$ & LPT & {$[1 \%, 3 \%]$} & 100 \\
Fault & FAN & {$[2 \%, 4 \%]$} & 100 \\
& BST & {$[1 \%, 3 \%]$} & 100 \\
& HPC & {$[2 \%, 4 \%]$} & 100 \\
& FAN & {$[1 \%, 3 \%]$} & \\
& BST & {$[1 \%, 4 \%]$} & 100 \\
& HPC & {$[0.5 \%, 2 \%]$} & \\
& HPT & {$[1 \%, 3 \%]$} & 200 \\
& LPT & {$[1 \%, 3 \%]$} & \\
\hline $\begin{array}{l}\text { Single and } \\
\text { Multiple } \\
\text { Actuator } \\
\text { Fault }\end{array}$ & WF36 & $5 \%$ & 150 \\
\hline
\end{tabular}

and flow capacity are shifted randomly within the range shown in the table. This range is considered to encompass any reasonable failure scenarios. All component shifts are made in the negative direction, except for HPT and LPT flow capacities which are shifted in both positive and negative directions. The actuator bias is also varied randomly in both positive and negative directions within the specified range. The actuator bias range is shown in percent of full-scale values.

For the 3000 test cases evaluated (the 1000 fault scenarios shown in table 6 at each of the three power settings), no misclassifications were encountered. This demonstrates the significant robustness of the FDI system to component and actuator faults. This robustness is largely due to the Kalman filter with tuning parameters. If this filter is not included, the FDI system is more likely to misclassify faults. To verify this claim, the FDI system was "standardized" by removing the Kalman filter with tuning parameters and then re-evaluated. For the 1000 fault scenarios at each of the three power settings, the number of component/actuator fault cases that this "standard" FDI system misclassified as a sensor fault were as follows: 97 (PLA=50), 113 (PLA=60), and 108 (PLA=68).

During the evaluation of the "robust" FDI system (the Kalman filter with tuning parameters included), it was noted that, in some of the fault scenarios, a threshold violation occurred for all Kalman filters. If this happens, the FDI system indicates that a large component/actuator fault may have occurred (see table 1).

\section{Evaluation 4: Robust Sensor Isolation}

All engine components gradually degrade with time due to usage. As discussed earlier, the baseline degradation (shift in all health parameters from the healthy baseline) can be tracked by ground-based trend monitoring systems, and the estimated baseline degradation can be used to update the FDI system for in-flight fault diagnostics. It is unlikely that the estimated baseline degradation will match perfectly with the actual condition. In order to assess the influence of baseline mismatch on the sensor fault isolation performance, the FDI system is evaluated in the presence of the error in the estimated baseline degradation.

In this test case, the estimated baseline is set to the healthy baseline condition (i.e., a trend monitoring system concluding that the engine is healthy), and consequently the design of the FDI system is based on a healthy engine. This FDI system is then applied to the nonlinear engine simulation with small baseline degradation. A $0.3 \%$ shift is injected to all 10 health parameters. With this magnitude, the FDI system indicates that no fault exists in the system at the three power settings (see table 5). In the presence of this baseline degradation mismatch, a bias is injected into each sensor. Table 7 shows the minimum positive bias isolated by the FDI system. Again, the numbers are given in percent of the steady-state values at the maximum power setting (PLA=72).

All sensor biases were isolated correctly, except for one case where the XN25 sensor is biased at a PLA setting of 68 degrees. As discussed before, the isolation of the XN25 sensor 
is very difficult at high power settings because of the large offnominal shift in the VSV and WF36 command inputs. As a result, the XN25 sensor bias is misclassified as a component/actuator fault. Since it is known that the XN25 sensor bias causes large shifts in multiple parameters (one sensor and two actuator commands), some intelligence must be built in to the FDI system to account for this knowledge. In the rest of the scenarios, the FDI system exhibits good performance. For some sensors, smaller bias can be isolated compared to the results shown in table 4. The worst case, or the largest minimum bias value that could be isolated, is the $6.0 \%$ PS3 sensor bias. It is especially encouraging that the FDI system did not attribute a fault in one sensor to a different sensor which, if it had occurred, would have created a very challenging environment for further accommodation steps.

\section{Table 7. Minimum Positive Bias Isolated by the Sensor FDI System in the Presence of $0.3 \%$ Baseline Degradation Mismatch}

\begin{tabular}{|c|c|c|c|}
\hline & PLA=50 & PLA=60 & PLA=68 \\
\hline XN12 & 1.7 & 2.1 & 2.3 \\
\hline XN25 & 4.3 & 3.8 & Misclassification \\
\hline P25 & 3.0 & 3.7 & 4.9 \\
\hline T25 & 2.2 & 2.1 & 2.0 \\
\hline PS3 & 2.8 & 4.5 & 6.0 \\
\hline T3 & 3.1 & 3.9 & 4.5 \\
\hline T49 & 1.9 & 2.4 & 2.7 \\
\hline
\end{tabular}

\section{DISCUSSION}

In-depth evaluation is a critical part in the development of an in-flight FDI system. The multiple objectives that the FDI system must handle often conflict with each other. Consequently, enhancing one aspect of the FDI performance does not necessarily result in the enhancement of overall performance. For instance, the minimum sensor bias magnitudes that the FDI system can isolate may be reduced by setting detection thresholds at a lower value. This modification, however, may result in increased false alarms and misclassifications. Through extensive evaluation, the FDI system can be matured to a point where its overall performance is satisfactory. To reach such a mature point, the sensor FDI system developed in this paper needs further evaluation and enhancement. Some of the issues that must be addressed in future work are discussed below.

First, the ambient conditions over which the FDI system can operate must be expanded. In the real environment, the ambient condition continually changes even in the cruise phase. As discussed earlier, this expansion can be accomplished by correcting the parameters of the Kalman filters based on inlet pressure and temperature measurements. In this "corrected" dimension, the FDI system must be evaluated for its diagnostic performance, sensitivity to ambient condition changes, and sensitivity to inlet sensor faults.
The evaluation results presented in this paper were obtained at fixed PLA values or fixed target low-pressure spool speeds (a fixed PLA value does not necessarily mean a fixed steady-state condition when faults are present in the system). Since the PLA movement is expected to be small in the cruise phase of a commercial aircraft, the FDI system was developed to be robust enough to handle small PLA movements, i.e., false alarms are not generated during minor transients. When the FDI system operates under relatively large PLA movements, however, some of the sensor estimates lag behind the actual measurements, causing an increase in the fault indicator signals. Eventually, the fixed detection thresholds are exceeded, and false alarms are generated. To account for relatively large PLA movements, adaptive detection thresholds which vary with transient conditions need to be introduced, as done in reference [1]. Then, the FDI system needs to be evaluated for its diagnostic capability during PLA transients.

\section{CONCLUSION}

An approach based on a bank of Kalman filters was investigated for the development of an aircraft engine sensor fault detection and isolation (FDI) system. This approach utilizes multiple Kalman filters, each of which is designed based on a specific fault hypothesis. When the propulsion system experiences a fault, only one Kalman filter with the correct hypothesis can maintain the nominal estimation performance. Based on this knowledge, the isolation of faults is conducted. The sensor FDI system developed in this paper utilizes a bank of $(m+1)$ Kalman filters where $m$ is the number of sensors being monitored. The additional Kalman filter is used to detect component and actuator faults. With this setup, the isolation of sensor faults or the detection of component/actuator faults can be achieved.

The sensor FDI system was applied to a commercial aircraft engine simulation, and its performance was evaluated at multiple power settings at a cruise operating point. After an extensive evaluation, the following three conclusions can be made: 1) the FDI system can correctly isolate a faulty sensor, 2) the FDI system can tolerate variations in sensor noise and model uncertainty, and 3) the FDI system is robust to component and actuator faults in terms of avoiding misclassifications. Some difficulties in isolating faults in two sensors due to the influence of the engine control system were noted. Further study is needed in the area of integration with control systems for performance improvement of the FDI system.

\section{REFERENCES}

[1] Merrill, W.C., DeLaat, J.C., and Bruton, W.M., 1988, "Advanced Detection, Isolation, and Accommodation of Sensor Failures-Real-Time Evaluation.” Journal of Guidance, Control, and Dynamics, 11, pp. 517-526. 
[2] Kobayashi, T., and Simon, D.L., 2003, "Application of a Bank of Kalman Filters for Aircraft Engine Fault Diagnostics," ASME Paper GT2003-38550.

[3] Volponi, A.J., 1994, "Sensor Error Compensation in Engine Performance Diagnostics,” ASME Paper 94-GT-58.

[4] Doel, D.L., 2003, "Interpretation of Weighted-LeastSquares Gas Path Analysis Results," Journal of Engineering for Gas Turbines and Power, 125, pp. 624-633.

[5] Kobayashi, T., and Simon D.L., 2001, "A Hybrid Neural Network-Genetic Algorithm Technique for Aircraft Engine Performance Diagnostics," Paper AIAA-2001-3763.

[6] España, M.D., 1993, "On the Estimation Algorithm for Adaptive Performance Optimization of Turbofan Engines," Paper AIAA-93-1823.
[7] Volponi, A.J., DePold, H., Ganguli, R., and Chen, D., 2000, "The Use of Kalman Filter and Neural Network Methodologies in Gas Turbine Performance Diagnostics: A Comparative Study," ASME Paper 2000-GT-547.

[8] Kerr, L.J., Nemec, T.S., and Gallops, G.W., 1991, "RealTime Estimation of Gas Turbine Engine Damage Using a Control Based Kalman Filter Algorithm," ASME Paper 91GT-216.

[9] Brotherton, T., Volponi, A., Luppold, R., and Simon, D.L., 2003, "eSTORM: Enhanced Self Tuning On-Board Real-Time Engine Model," Proceedings of the 2003 IEEE Aerospace Conference, Big Sky, MT. 
Public reporting burden for this collection of information is estimated to average 1 hour per response, including the time for reviewing instructions, searching existing data sources, gathering and maintaining the data needed, and completing and reviewing the collection of information. Send comments regarding this burden estimate or any other aspect of this collection of information, including suggestions for reducing this burden, to Washington Headquarters Services, Directorate for Information Operations and Reports, 1215 Jefferson Davis Highway, Suite 1204, Arlington, VA 22202-4302, and to the Office of Management and Budget, Paperwork Reduction Project (0704-0188), Washington, DC 20503.

\begin{tabular}{|l|l|l|}
\hline 1. AGENCY USE ONLY (Leave blank) & $\begin{array}{c}\text { 2. REPORT DATE } \\
\text { August } 2004\end{array}$ & $\begin{array}{c}\text { 3. REPORT TYPE AND DATES COVERED } \\
\text { Technical Memorandum }\end{array}$ \\
\hline
\end{tabular}

\section{TITLE AND SUBTITLE}

5. FUNDING NUMBERS

Evaluation of an Enhanced Bank of Kalman Filters for In-Flight Aircraft Engine

Sensor Fault Diagnostics

\section{AUTHOR(S)}

Takahisa Kobayashi and Donald L. Simon

WBS-22-728-30-05

1L161102AF20

\section{PERFORMING ORGANIZATION NAME(S) AND ADDRESS(ES)}

National Aeronautics and Space Administration

John H. Glenn Research Center at Lewis Field

Cleveland, Ohio 44135-3191

8. PERFORMING ORGANIZATION

REPORT NUMBER

E-14712

\section{SPONSORING/MONITORING AGENCY NAME(S) AND ADDRESS(ES)}

National Aeronautics and Space Administration

Washington, DC 20546-0001

and

U.S. Army Research Laboratory

Adelphi, Maryland 20783-1145
10. SPONSORING/MONITORING AGENCY REPORT NUMBER

NASA TM-2004-213203

ARL-TR-3252

GT2004-53640

\section{SUPPLEMENTARY NOTES}

Prepared for the Turbo Expo 2004 sponsored by the American Society of Mechanical Engineers, Vienna, Austria, June 14-17, 2004. Takahisa Kobayashi, QSS Group, Inc., Cleveland, Ohio 44135; and Donald L. Simon, U.S. Army Research Laboratory, NASA Glenn Research Center. Responsible person, Takahisa Kobayashi, organization code 5530, 216-433-3739.

12a. DISTRIBUTION/AVAILABILITY STATEMENT

12b. DISTRIBUTION CODE

Unclassified - Unlimited

Subject Category: 07

Distribution: Nonstandard

Available electronically at http://gltrs.grc.nasa.gov

This publication is available from the NASA Center for AeroSpace Information, 301-621-0390.

13. ABSTRACT (Maximum 200 words)

In this paper, an approach for in-flight fault detection and isolation (FDI) of aircraft engine sensors based on a bank of Kalman filters is developed. This approach utilizes multiple Kalman filters, each of which is designed based on a specific fault hypothesis. When the propulsion system experiences a fault, only one Kalman filter with the correct hypothesis is able to maintain the nominal estimation performance. Based on this knowledge, the isolation of faults is achieved. Since the propulsion system may experience component and actuator faults as well, a sensor FDI system must be robust in terms of avoiding misclassifications of any anomalies. The proposed approach utilizes a bank of $(m+1)$ Kalman filters where $m$ is the number of sensors being monitored. One Kalman filter is used for the detection of component and actuator faults while each of the other $m$ filters detects a fault in a specific sensor. With this setup, the overall robustness of the sensor FDI system to anomalies is enhanced. Moreover, numerous component fault events can be accounted for by the FDI system. The sensor FDI system is applied to a commercial aircraft engine simulation, and its performance is evaluated at multiple power settings at a cruise operating point using various fault scenarios.

\section{SUBJECT TERMS}

Aircraft engines; Systems health monitoring; Gas turbine engines; Flight safety; Fault diagnostics; Kalman filter

\begin{tabular}{|c|c|}
\hline $\begin{array}{c}\text { 17. SECURITY CLASSIFICATION } \\
\text { OF REPORT } \\
\text { Unclassified }\end{array}$ & $\begin{array}{c}\text { 18. SECURITY CLASSIFICATION } \\
\text { OF THIS PAGE } \\
\text { Unclassified }\end{array}$ \\
\hline
\end{tabular}

19. SECURITY CLASSIFICATION OF ABSTRACT

Unclassified
15. NUMBER OF PAGES

17

16. PRICE CODE

20. LIMITATION OF ABSTRACT

Standard Form 298 (Rev. 2-89)

Prescribed by ANSI Std. Z39-18 298-102 

